\title{
Use of Scratch for the Teaching of Second Languages
}

\author{
https://doi.org/10.3991/ijet.v14i21.11217 \\ Antonio Sarasa-Cabezuelo \\ Universidad Complutense de Madrid,Madrid, Spain \\ asarasa@ucm.es
}

\begin{abstract}
In recent decades, the use of new technologies in the field of language teaching has been introduced in a variety of ways. Some examples are the evaluation through the use of applications that make it possible to carry out level tests or examinations, the creation in digital format of the contents that traditionally were used in physical format, and mobile apps that make it possible to reach a certain level of language proficiency. Scratch is a visual programming language created to teach the basics of programming. However, language features that are useful for teaching in other knowledge domains. In this article, the use of Scratch is described as a tool that can be useful for teachers and students in the acquisition of second languages.
\end{abstract}

Keywords-Educational programs, Educational technology, Computer aided instruction, Education courses

\section{Introduction}

One of the most important objectives in the teaching of second languages is to ensure that students acquire the skills to face various communicative activities of production and comprehension, both orally and in writing [14], of the language under study. To achieve this goal, the teacher uses different resources that will provide the student with a set of comprehension strategies (identification of keys and inferences) and production (planning, compensation, control and correction) useful to acquire different communication skills in the language of study [27]. In the case of listening comprehension, you need to listen to sound learning resources in the language of study such as public statements, media, songs, lectures, private conversations, etc. In the case of reading comprehension, you need to read different types of text documents written in the language of study such as instructions, newspapers, magazines, opinion articles, literary texts.... In the field of audiovisual understanding, it is necessary to access multimedia resources such as television programs, fiction films, reports, etc. And finally, for the activities of expression, interaction or mediation, it is necessary to be able to try different production models (public presentations, oral monologues, written essays, etc.) [32]. Second-language teaching involves [39], among other aspects, the acquisition of the ability to face various language communication activities and the strategies required to do so [14]. Essentially, these are divided into oral and written production and comprehension activities [42]. To make students skillful in 
these activities, teachers must use various resources and strategies [15]. Thus, to work on aural comprehension, students must listen to public statements, media, conferences, private conversations, etc. The same happens with reading comprehension, where students must be able to read different types of documents (instructions, opeds, literary texts, etc.) and audiovisual comprehension, in which access to TV programs, films, news, etc. is necessary[48]. As for expression activities, students must be able to try various production models (public presentations, oral monologues, written essays, etc.) [32].The goal of all these resources and activities is to provide students with various comprehension (identification of key points and inferences) and production (planning, compensation, control, and correction) strategies. The same goes for interaction or mediation activities [27].

In order to find to what extent someone is skillful in the various communicational activities, models have been designed to structure the competences achieved at various skill levels. Each level is described by ta set of characteristics that must be observable in an adult. Without a doubt, the most widespread model in Europe is the Common European Framework of Reference for Languages (CEFRL) developed by the European Council. This model provides an international pattern to measure the level of comprehension and oral and written expression in a language. To this end, it defines a set of common reference levels (A1, A2, B2, B2, C1, and C2) that provide stages for mastery of a language [35]. Thus, $\mathrm{A} 1$ and $\mathrm{A} 2$ would correspond to a basic user, $\mathrm{B} 1$ and $\mathrm{B} 2$ to an independent user, and $\mathrm{C} 1$ and $\mathrm{C} 2$ to a competent user [21].

In order to develop these learning resources, teachers have made use of the technological resources at each point in time. Thus, immediately before the introduction of new technologies, physical means were usually employed, such as [38] books providing the grammar contents and the exercises to exercise vocabulary and grammatical structures, reading books in the language being studies, adapted to the various skill levels, bilingual printed dictionaries, tapes or discs with sound recordings used for aural comprehension, videos to work on audiovisual comprehension (verbal and nonverbal language), vocabulary flash cards, etc. These resources were effective (and in fact some of them are still used), but they had some limitations which will be discussed [40]. Firstly, the creation of these resources was fully manual and physical, so that the financial and time cost of reproducing any of these resources was significant. In addition, access to resources was limited [18], as using them required having physical access to the resource (e.g. if a reading book or dictionary was needed, it had to be purchased or borrowed from library. Likewise, there was no possibility of accessing the audio used in class in most cases, as it was only available to the teacher). From the student's point of view [7], resources in general were rigid as regarded their ability to adapt the different learning styles. They were conceived for a standard student, so that the resources were not useful to those who did not meet those conditions. Likewise, in many cases, it was difficult or impossible to use them autonomously, as they were conceived for use requiring the presence of a teacher [11]. In this regard, feedback for an exercise done was not obtained immediate, as it required giving it physically for the teacher to correct it. From the teacher's point of view [23], the main limitation was evaluation. In most cases it consisted [46] in a written examination, with different types of questions (true or false, fill-the-gap and grouping questions, writing 
a text...), an oral expression test by means of a conversation with the teacher, an aural comprehension test consisting of questions on the contents of an audio recording that had been played, and a written comprehension test making questions about a text read by the students. Even though this kind of evaluation test is still performed, as they were not conducted digitally, their execution was more complex and their correction was delayed [13].

Use of the new technologies has had various significant effects (both on education in general and on the teaching of second languages specifically) [19]. Firstly, attempts have been made to reproduce both the learning resources and strategies that were physically used [3] (e.g. physical dictionaries have led to online dictionaries; printed evaluation tests have been replaced by automatic evaluation tools, etc.) [9]. In other cases, replacement has not been total, but rather new technologies have been applied as supplementary or supporting tools [4] in addition to the resources that had been used until then. Another consequence of the use of new technologies is access by both teachers and students to new possibilities and features which had previously not existed or were not possible with physical means [44].

Thus, currently contents that can be dynamically adapted to a student's learning level or style can be accessed. There is also the possibility of receiving immediate feedback on the activities performed by the learner or the exercises solved. Thanks to the new technologies, digital repositories including audio and video recordings, as well as contents specifically prepared for second-language teaching are available [29], which can be accessed through a computer with an Internet connection. Various specific language teaching tools are available, with different functions:

- Evaluating pronunciation and oral expression [24]

- Evaluating skills when writing and using the grammar or vocabulary of a language

- Correcting mistakes and giving feedback or an evaluation report; iv) helping to translate a text fragment, etc.

Thus, it could be said that what essentially characterizes the use of the new technologies in this field is [34] easy, quick, and universal access to resources, the range of contents that can be specifically used for language learning, and the variety of tools to evaluate linguistic skills semiautomatically, providing almost instantaneous feedback to students [8].

However, a problem that arises in this context is precisely the range and number of available tools and applications, which make it hard to know which to select and how to use them in a coordinated and consistent way [41]. This paper describes a proposed solution to this problem, based on the use of the programming language Scratch. This is a visual programming language conceived to intuitively teach and introduce the basics of programming, but its use is not restricted to this field.

The paper is structured as follows. Section 2 briefly describes how the new technologies are being used in some second-language learning tasks. Section 3 provides a brief introduction to Scratch. Then, Section 4 describes a proposal for use of Scratch according to the various CEFRL levels. Finally, a number of conclusions and lines for future lines will be expounded. 


\section{Use of the New Technologies in Language Teaching.}

The experimental work is based on the analysis of the answers given by a sample of teachers of second languages to a questionnaire. Teachers are the best source of information on the difficulties they have to teach and on the problems they observe in students to learn. In this sense, the objective of this questionnaire was to know the opinion of teachers of second languages about the problems that their students have in the process of acquiring a foreign language. Next, we will describe the instrument of the experiment and the characteristics of the sample used in it. New technologies are being extensively used in second-language teaching. This section provides a brief review of the main areas of application:

- Lexicon acquisition. Traditionally, this aspect was worked on by means of tools based on exercises in which the vocabulary to be learnt is used repeatedly and in different ways in order to fix it. This basic repetition mechanisms is implemented in various ways: flashcards, mnemotechnics, and gamification. In the case of flashcards, applications simulate cards on which a term is printed on one side and the other side shows an example of use of that term, its translation, or its meaning. There are usually divided by linguistic competence level, and are adapted to the student's learning style, so that the periods of repetition and difficulty of the cards increase or decrease according to the student's progress. Some applications also make it possible to design your own flashcards or even import those created by others. One example is the Anki tool [47]. Regarding mnemotechnics, its goal is learning through the association of ideas. To this end, the applications give students the possibility of associating the terms which they wish to memorise with an image, sound, idea, or story connected to them. One example is the Menrise application [45]. Finally, there are tools that use gamification. In this case, the goal is to make use of the motivation elements offered by games and competition to facilitate study in a fun way. One outstanding example is the Duolingo application [45]. This application makes intensive use of game-based motivational factors. For example, it has a reward system that rewards achievements (going one level up, passing a unit, etc.), it uses a virtual mascot in the shape of an owl that periodically tells the user that he or she must continue to study the language, and makes it possible to follow other people's achievements, so that competition is encouraged. In addition, the exercises proposed are divided by linguistic competence and by difficulty level, and the repetition of terms in the various exercises is used as the basic tool to achieve learning. Other additional means being used for the acquisition of vocabularies are e-books and in general document reading applications that integrate an online dictionary, which makes it easy for students to immediately find the meaning of unknown terms.

- Written interaction. In this regard, two main tools are being used: wikis and blogs [33]. A wiki is an online tool designed to facilitate collaborative written production. In general, any changes made in a wiki can be published without requiring previous approval or minimum restrictions are required. Wikis are used in secondlanguage teaching in very different ways such as [48] direct written expression ac- 
tivities (proposing a specific topic on which the student must write a free text. Sometimes the use of a certain lexicon or syntactic structures is proposed), discussion of a text (the text is provided and students must give their views on it), collaborative creation of a glossary for a book which all the students have read [43], improvement of a text (a text with mistakes is given, and students are individually or collaboratively asked to syntactically and semantically improve the contents of the text, or even to change its literary genre). By contrast, blogs are online applications that also facilitate written production, but, unlike wikis, they are conceived for individual use. A blog works as a repository of text entries in which the authors gives his or her views or offers information in a specific topic [2]. This tool is usually employed as a means to encourage students to develop their written expression [33]. It offers interesting motivational factors, such as the public nature of blog entries, the possibility of having followers and receiving comments from other people. Likewise, use of the blog makes it possible to develop expression and use of the lexicon in the specific domain of the topic of the blog, as it forces student to find, master, and use the terminology for that domain. Likewise, a blog allows teachers to correct, through the comments, any mistakes made or simply suggest how students can improve their writing.

- Oral interaction. There are two types of software that are used in general, for the creation and edition of video and audio [10]. There is a vast number and variety of tools, and they are mainly used [25] for aural comprehension (a video or audio recording is played and its comprehension is tested by means of questions), oral production (students record a video or audio. Sometimes the topic, vocabulary, and linguistic competence level to be used are suggested), or both activities in combination (a video or audio already produced is used, and students must edit it in different ways, e.g. adding subtitles to a video, changing the video audio track or language, recording an audio track and inserting it in a video) [47].

- Pragmatics and culture. One tool that is very frequently used in this field is video and audio recording on cultural or social topics [22]. These videos are a very valuable tool to learn the natives' non-verbal language and audio files can be useful to learn the linguistic turns of a language, irony, jokes, etc. In addition, virtual museums are another very useful tool for cultural, with Google Arts being particularly outstanding (https://www.google.com/culturalinstitute/beta/ [accessed 11/06/2019]). This is a Google initiative to digitalize the art collections of the world's great museums. It enables users to digitally access the collections, and in particular makes it possible to select some works to create your own collections and share them with other users. This makes it easier for teachers to use certain cultural and historic aspects regarding the language being studied which can help students to learn more about cultural pragmatics.

- Evaluation. A wide range of tools have also been developed for this purpose [30], ranging from those that simulate classic evaluation processes, offering the functionality required to create different kinds of questions (true/false, association, multiple-choice, free text, etc.) to those that use gamification as the common thread for evaluation (these are games where evaluation usually takes the form of passing cer- 
tain tests that are contextualized within the game. They also add motivational elements typical of gamification, such as participants' scores, etc.)

- Other elements. There are other areas of second-language teaching in which the new technologies are being used: i) online dictionaries or translation tools; ii) video conferences [16], which, among other possibilities make it possible to practise aural comprehension in real time [31], teaching lessons, or answering questions; iii) the use of social media [5], such as Twitter [20], for vocabulary acquisition, written production, or aural comprehension through video links, etc.

- As we have seen, ICTs adequately cover second-language acquisition learning needs. However, they have some limitations, such as the following [17]:

- Lack of integration, as they are run on different platforms and in most cases they cannot be run in combination (it is true that some LMSs jointly offer many of the tools mentioned, but with certain functionality limitations).

- Lack of configuration. In some of the tools discussed, contents cannot be edited (the contents being offered must be exclusively used), or they offer minimal configuration (they do not make it possible to adapt functionality to different learning or execution styles).

- They have limitations as regards the possibilities of innovation and creativity which they offer teachers for the activities and exercises proposed to students, as new functionalities cannot be added and existing ones cannot be modified.

- For this reason, it would be useful to have a tool that would make it possible to replicate some of the functionalities of the tools discussed, facilitating their adaptation and making it possible to add other functions.

\section{The Scratch programming language.}

Scratch is a visual programming language created at MIT [1], in order to intuitively arouse and encourage computational thought and increase the development of mental skills. Its main area of application is non-university education. The goal is learning how to program without any previous knowledge, from a constructionist point of view (that is, learning by doing). In this regard, the Scratch programming language is characterized by the fact that it provides the main resources to program available to a typical programming language, with the difference that they are accessed through graphic icons shaped like the pieces of jigsaw, which internally represent a control structure or a data type.

Thus, programming teaching is metaphorically explained as the assembly of jigsaws for which the right pieces must be selected and correctly pieced together in order to implement a certain action. In addition, Scratch has a number of visual objects called sprites, various aspects of which, such as their color, size, shape, movements, sounds played, etc. can be configured. In this way, a Scratch program is an animated interaction between one or more sprites which are associated with a behavior or actions to be performed, which are programmed by means of one or more jigsaws representing those actions. One of the main programming resources provided by Scratch is event-based programming [36], which makes it possible to intuitively establish certain 
behaviors or actions that emerge in interaction depending on whether an event takes place or not.

The success of this simple programming language is due to several factors [28], mainly the use of typical gaming elements to motivate and facilitate the learning of programming, the possibilities for innovation and creativity offered to create educational resources in the form of animated stories [12], the great capacity for configuration and adaptability (as own or created images, backgrounds, and sounds can be used), and the vast number of available resources to work with Scratch [37], given that the software as well as the programs created are free, and anyone can access the programs created by other people, copy them, reuse them, modify them, etc. Likewise, the project gives users a set of supporting learning materials, such as manuals, videos, FAQs, and support for teachers. Scratch can be used online or installed as a desktop application.

\section{$4 \quad$ Results}

This section provides several strategies to use Scratch in second-language teaching, taking the needs discussed into account.

- Lexicon and grammar acquisition. One way to create an exercise that promotes vocabulary learning is to select a specific information domain and prepare an animated story showing visual or sound items that represent the domain terms that must be learnt. Students can interact with a character that leads the learning process. They can click on each of the items with the mouse, or else the character can ask students directly about a specific item. Depending on the answer given, feedback would be given on whether it is correct or no. Figure 1 shows an example of this strategy, together with a representative piece of code. It is a vocabulary acquisition project for level A of Spanish as a second language, where the domain is represented by the rooms in a flat (https://scratch.mit.edu/projects/38037250).
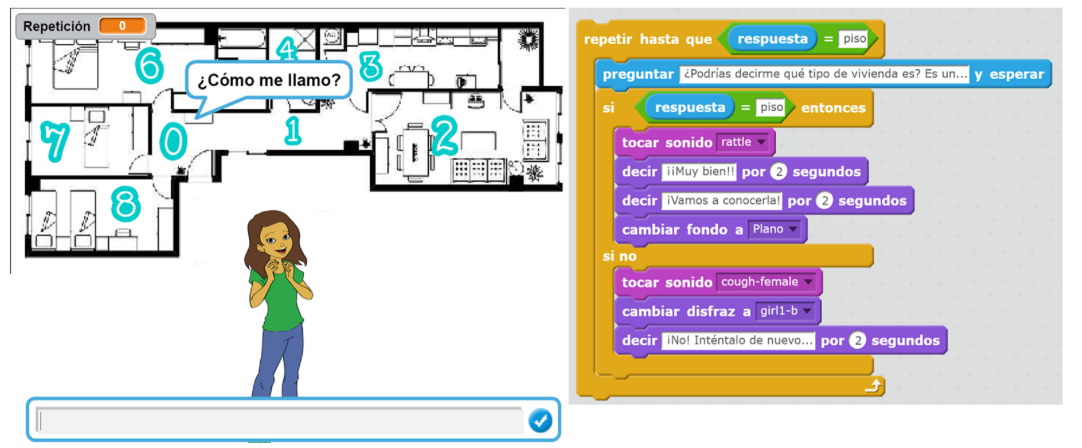

Fig. 1. Program to acquire vocabulary through the rooms in a flat.

To program the story, the following tasks were performed: i) Finding and loading the representative elements for the domain: pictures of the areas in a flat; ii) Creating 
items that represent the terms in the lexicon; iii) Associating an event with each item, so that, when a student clicks on it, a question and a text field will be shown, asking the student to enter the student to enter the term that names that item; iv) By means of a conditional structure, it is verified whether the answer is correct or not. If it is correct, positive feedback is given, and if it is not, the student is asked again until the right answer is obtained.

One variant of this strategy involves using gamification elements, such as earning points for the right answers, a maximum number of failures, a maximum time to complete the exercise, etc. Figure 2 shows an example of this approach together with a code block. Its goal is to review irregular verbs in an English class (https://scratch. mit.edu/projects/131105620/). The program directly asks students about the terms, and if the answer is right, the student earns points, and, if he or she fails, lives are deducted. From the programming point of view, the innovation consists in using different variables to record the points accumulated and the lives lost, so that the loop that controls the interaction is run whenever lives have not been exhausted or all the answers have been answered with at least one life.

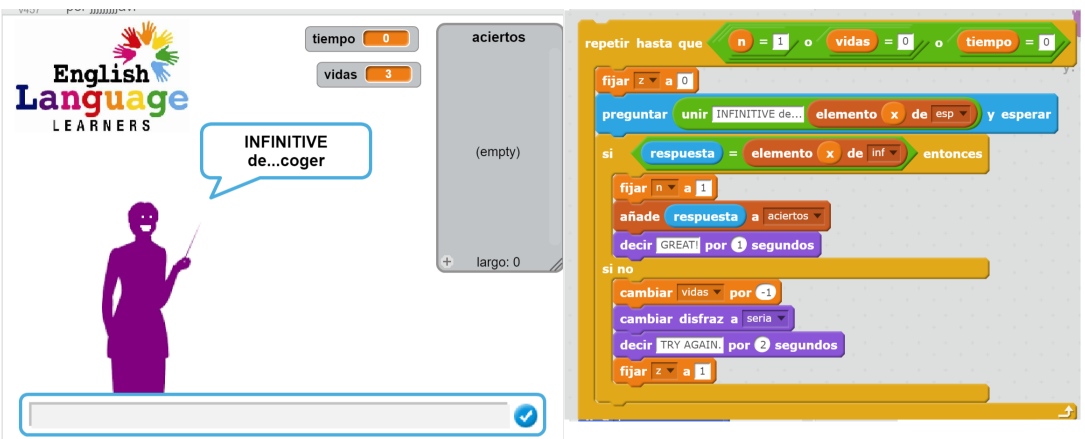

Fig. 2. Program to review English vocabulary.

One final possibility is framing the story within a game, where students are given a task to perform using a character that can move through various scenarios and interact with objects or other characters found, as in a video game. Figure 3 shows an example of this approach, together with a representative code block (https://scratch.mit.edu/projec $\underline{\mathrm{ts} / 2642836 /)}$. 

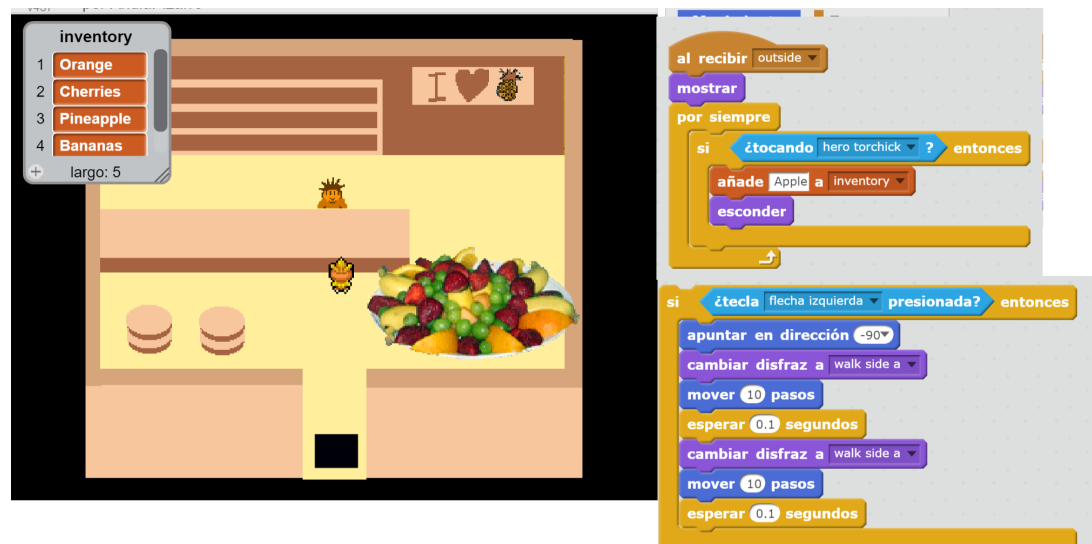

Fig. 3. Program to review English vocabulary.

The goal is to review fruit vocabulary in an English class. Students use a character to move through various scenarios and recover icons that represent fruits. For each item recovered, the student is shown what that item is called in English. From the programming point of view, the main innovation is the code blocks that enable the character to move through the various scenarios, as shown in the second code block in Figure 3.

- Aural comprehension. One strategy to work on this skill consists in creating a program that simulates a dialogue, including interactions with the student, who is asked about the topic of the conversation. Subtitles could be added to encourage aural comprehension. Depending on the student's answers, the program would provide feedback on whether they are correct. Figure 4 (https://scratch.mit.edu/projects/ $\underline{16127173 /)}$ ) shows an example of this approach as part of an aural and written comprehension project for the teaching of English at level A. The program includes several characters that have a dialogue and sometimes interact with users, asking them question. Each character's conversations also appear transcribed in the characters' speech bubbles.

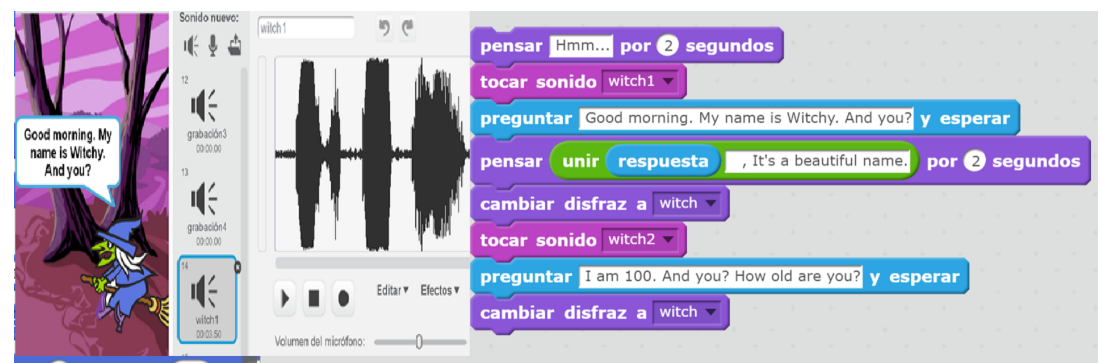

Fig. 4. Program implementing a dialogue in English. 
The main innovation with respect to programming in the previous example is the inclusion of audio. In order for characters to have conversations, teachers must previously record them, which can be done from the Scratch editor or else from outside Scratch, adding the sound to the program. Then the relevant character must be associated with the audio file in which the conversation was recorded. Moreover, when the interaction is programmed, it must be specified that the audio file must be played just as the character appears (a character can be associated with a set of audio files, but when programming it must be decided which audio file is to be played at each point).

Figure 4 shows the audio file that contains the sentence spoken by the character in the previous example, and the code block that uses that audio file. One advantage of this strategy is the possibility of reuse offered, in different ways. Firstly, one same program can be easily adapted to other languages, as it is enough to record the characters' conversations in the preferred language and add them. In addition, this kind of program can serve as the basis for other aural comprehension exercises, such as adding subtitles or speech bubbles, or even asking students to make up (and record) a full story involving the characters.

Another strategy involves the use of songs. To this end, a song is played, and the program simultaneously shows the lyrics for the song. This type of exercise encourages both aural comprehension and written comprehension, given that students are able to compare what they understand in the audio file and what is being actually played. The advantage of this strategy is the student's motivation when using songs (which are usually appealing for students). Figure 5 shows an example of this approach, in which a song is played, while the lyrics of the song being played are displayed on the screen at the same time.

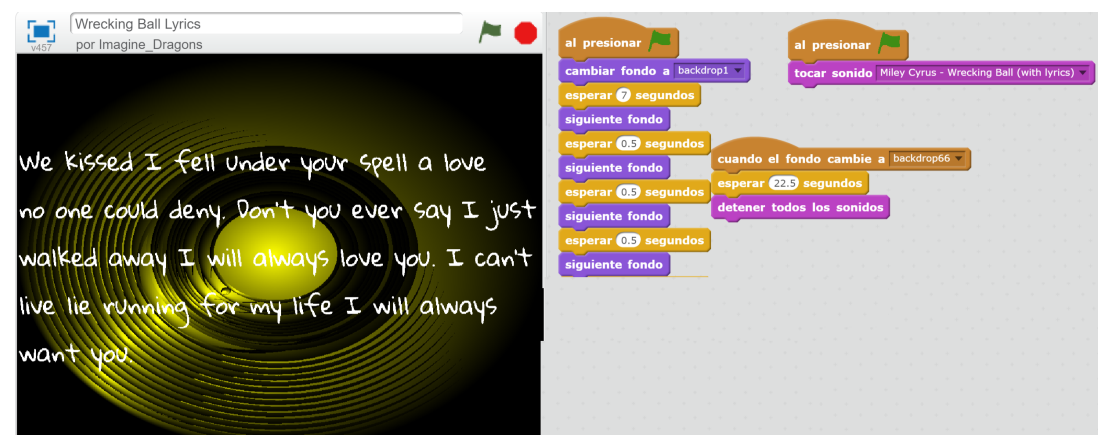

Fig. 5. Program playing a song and its lyrics.

From the programming point of view, the innovation consists in the playing of the song and its synchronization with the song lyrics. To this end, the teacher must obtain the audio file and the lyrics for the song. In this case, there are no characters, and the complexity lies in counting the points in time when the piece of the song lyrics displayed on the screen must be changed so that it corresponds to the part of the audio file being played. The program is structured on the basis of code blocks of the "wait $\mathrm{x}$ second and change the background" type. No action needs to be taken on the song, 
except playing it. This kind of exercise, similarly to the one above, can be used for transcription exercises.

- Written comprehension. The main strategy for this competence is based on the creation of a program that displays a text that can be part of a book or a story. The program can be accompanied by a set of questions after reading the text, to verify the student's level of comprehension. Figure 6 (https://scratch.mit.edu/projects/113090 196/) shows an example of this approach.

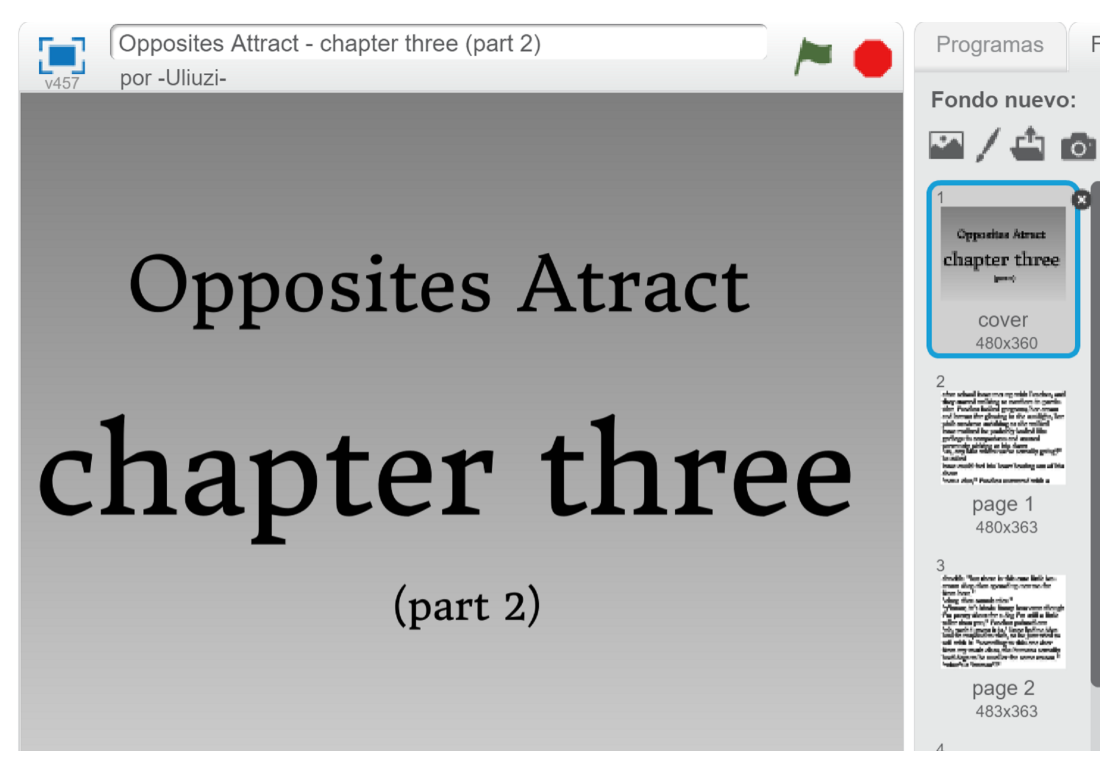

Fig. 6. Program implementing a book in chapters.

This is a book that has been implemented in several programs, where each one represents a chapter. From the programming point of view, implementation involves creating backgrounds with the text of the book, associating an event such as clicking on the space or else moving an arrow to move from one background to another, thus making it possible to read the book chapter.

Another strategy along the same lines is reading a text and verifying the student's comprehension level by means of a set of questions. Figure 7 (https://scratch.mit.edu/ projects/97766505/) shows an example of a program implementing a quiz on the Harry Potter books. A set of questions associated with a counter is sequenced, so that each correct answer is accumulated in the counter. 

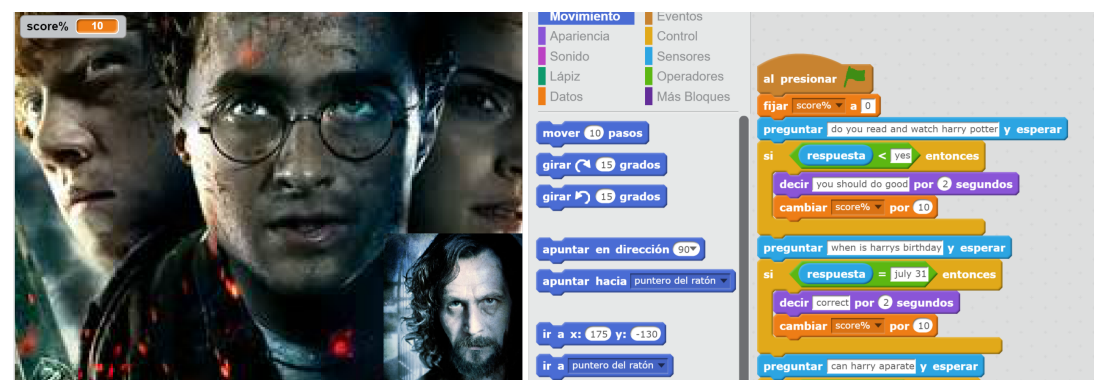

Fig. 7. Program implementing a quiz on the Harry Potter books.

- Pragmatics and culture. One potential strategy to teach the culture of the country where the language being studied is spoken is to create a virtual museum with outstanding cultural items. This interaction can be accompanied by questions about the cultural items displayed, like a culture quiz. Figure 8 (https://scratch.mit.edu/projects/ 175863521) shows an example of a virtual museum in which students walk through different rooms, where paintings are displayed, together with various associated questions (their title, author, when they were painted, etc.) Every time a question is correctly answered, points are added to an associated counter, and the student can move on to the next room.
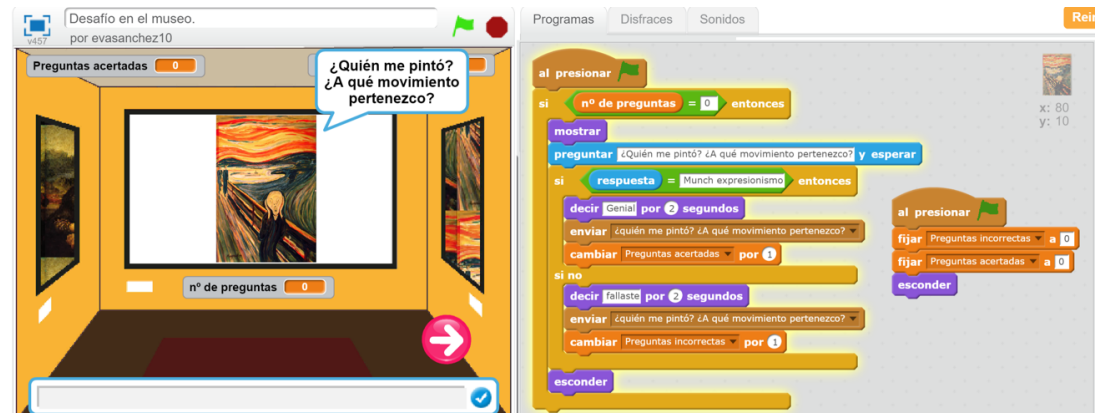

Fig. 8. Program implementing a virtual museum.

This template, modified in MS Word 2007 and saved as a "Word 97-2003 Document" for the PC, provides authors with most of the formatting specifications needed for preparing electronic versions of their papers. All standard paper components have been specified for three reasons:

- Ease of use when formatting individual papers

- Automatic compliance to electronic requirements that facilitate the concurrent or later production of electronic products

- Conformity of style throughout a conference proceedings

Margins, column widths, line spacing, and type styles are built-in; examples of the type styles are provided throughout this document and are identified in italic type, 
within parentheses, following the example. Some components, such as multi-leveled equations, graphics, and tables are not prescribed, although the various table text styles are provided. The formatter will need to create these components, incorporating the applicable criteria that follow.

\section{Conclusion}

The goal of this paper was to show the potential that the Scratch programming language has to be used as a teaching toll in second-language teaching. To do so, some potential strategies for use of language (and examples of their implementation) have been shown to cover some of the needs that arise in this kind of teaching.

Some of the characteristics that make its use interesting are: the easy way to create animated stories that are very appealing to students, the possibility of adding functionalities that can be as complex as desired (it is enough to program them on Scratch), the number of resources offered by Scratch to create stories (videos, sounds, images, etc.), the possibilities of reuse, given the free nature of the projects created with Scratch, and the ease of running Scratch programs (just a Flash player is required). Finally, we would like to highlight that use of Scratch not only helps students learning second languages, but also serves to familiarize them in an intuitive, fun way with programming and the new technologies.

The main future work is the publication of a book-manual describing the potential strategies for the application of Scratch in second-language teaching in more detail, illustrated by the creation of a full project.

\section{Acknowledgement}

This work was funded by eLITE-CM S2015/HUM-3426, RedR+Human (TIN2014 -52010-R) and CetrO+Spec (TIN2017-88092-R) projects.

\section{$7 \quad$ References}

[1] Aivaloglou, E., \& Hermans, F. (2016, August). How kids code and how we know: An exploratory study on the Scratch repository. In Proceedings of the 2016 ACM Conference on International Computing Education Research (pp. 53-61). ACM. https://doi.org/10.1145/29 60310.2960325

[2] Beatty, K. (2013). Teaching \& researching: Computer-assisted language learning. Routledge.

[3] Blake, R. J. (2009). The use of technology for second language distance learning. The Modern Language Journal, 93(s1), 822-835. https://doi.org/10.1111/j.1540-4781.2009.009 $\underline{75 . \mathrm{x}}$

[4] Blake, R. J. (2013). Brave new digital classroom: Technology and foreign language learning. Georgetown University Press. 
[5] Blattner, G., \& Lomicka, L. (2012). Facebook-ing and the social generation: A new era of language learning. Alsic. Apprentissage des Langues et Systèmes d'Information et de Communication, 15(1). https://doi.org/10.4000/alsic.2413

[6] Breen, M. (Ed.). (2014). Learner contributions to language learning: New directions in research. Routledge.

[7] Bygate, M., Skehan, P., \& Swain, M. (2013). Researching pedagogic tasks: Second language learning, teaching, and testing. Routledge.

[8] Chiu, Y. H. (2013). Computer-assisted second language vocabulary instruction: A metaanalysis. British Journal of Educational Technology, 44(2).

[9] Chun, D., Kern, R., \& Smith, B. (2016). Technology in language use, language teaching, and language learning. The Modern Language Journal, 100(S1), 64-80. https://doi.org/10. $\underline{1111 / \operatorname{modl} .12302}$

[10] Coniam, D. (2001). The use of audio or video comprehension as an assessment instrument in the certification of English language teachers: A case study. System, 29(1), 1-14. https://doi.org/10.1016/s0346-251x(00)00057-9

[11] Cook, V. (2013). Second language learning and language teaching. Routledge.

[12] Cornillie, F., Van den Branden, K., \& Desmet, P. (2015, January). From language play to linguistic form and back again. Lessons from an experimental study for the design of taskbased language practice supported by games. In Proceedings of XVIIth International CALL Conference. Task design and CALL. (pp. 214-222). Universiteit Antwerpen. https:// doi.org/10.1017/cbo9780511667282.002

[13] Crusan, D., Plakans, L., \& Gebril, A. (2016). Writing assessment literacy: Surveying second language teachers' knowledge, beliefs, and practices. Assessing Writing, 28, 43-56. https://doi.org/10.1016/j.asw.2016.03.001

[14] De Europa, C. (2002). Marco común europeo de referencia para las lenguas. Strasburgo: Consejo de Europa, Ministerio de Educación, Cultura y Deporte/Instituto Cervantes.

[15] Fernández, F. M. (2007). Adquisición de segundas lenguas y Sociolingüística. Revista de educación, 343, 55-70.

[16] García Pascual, E., and D’Angelo, L. (2008). Consideraciones metodológicas y organizativas para el desarrollo de videoconferencias con metodología CLIL en el marco de la convergencia europea. RIED. Revista iberoamericana de educación a distancia, 11(1). https:// doi.org/10.5944/ried.1.11.958

[17] Garrett, N. (2009). Computer-assisted language learning trends and issues revisited: Integrating innovation. The Modern Language Journal, 93(s1), 719-740. https://doi.org/10.111 1/j.1540-4781.2009.00969.x

[18] Godwin-Jones, R. (2010). Emerging technologies from memory palaces to spacing algorithms: approaches to second language vocabulary learning. Language, Learning \& Technology, 14(2), 4-11.

[19] Golonka, E. M., Bowles, A. R., Frank, V. M., Richardson, D. L., \& Freynik, S. (2014). Technologies for foreign language learning: a review of technology types and their effectiveness. Computer Assisted Language Learning, 27(1), 70-105. https://doi.org/10.1080/09 $\underline{588221.2012 .700315}$

[20] Hamid, S., Waycott, J., Kurnia, S., \& Chang, S. (2015). Understanding students' perceptions of the benefits of online social networking use for teaching and learning. The Internet and Higher Education, 26, 1-9. https://doi.org/10.1016/j.iheduc.2015.02.004

[21] Hartig, J., \& Harsch, C. (2017). Multidimensional Structures of Competencies: Focusing on Text Comprehension in English as a Foreign Language. In Competence Assessment in Education (pp. 357-368). Springer, Cham. https://doi.org/10.1007/978-3-319-50030-0_21 
[22] Hinkel, E. (Ed.). (1999). Culture in second language teaching and learning. Cambridge University Press.

[23] James, C. (2013). Errors in language learning and use: Exploring error analysis. Routledge.

[24] Jones, L. C. (2016). Using technology in language teaching and listening comprehension: Revisiting what teachers should know and do. IALLT Journal of Language Learning Technologies, 34(2). https://doi.org/10.17161/iallt.v34i2.8360

[25] Jordano de la Torre, M. (2011). La enseñanza-aprendizaje de la competencia oral en lengua extranjera en el contexto de la educación abierta ya distancia: de la casete a la interacción virtual. RIED. Revista iberoamericana de educación a distancia, 14(1). https://doi.org/ 10.5944/ried.1.14.798

[26] Kramsch, C. (1995). The cultural component of language teaching. Language, culture and curriculum, 8(2), 83-92. https://doi.org/10.1080/07908319509525192

[27] Larsen-Freeman, D., \& Long, M. H. (2014). An introduction to second language acquisition research. Routledge.

[28] Lawanto, K., Close, K., Ames, C., \& Brasiel, S. (2017). Exploring Strengths and Weaknesses in Middle School Students' Computational Thinking in Scratch. In Emerging Research, Practice, and Policy on Computational Thinking (pp. 307-326). Springer International Publishing. https://doi.org/10.1007/978-3-319-52691-1_19

[29] Levy, M. (2009). Technologies in use for second language learning. The Modern Language Journal, 93(s1), 769-782. https://doi.org/10.1111/j.1540-4781.2009.00972.x

[30] Leutner, D., Fleischer, J., Grünkorn, J., \& Klieme, E. (2017). Competence assessment in education: An introduction. In Competence Assessment in Education (pp. 1-6). Springer, Cham. https://doi.org/10.1007/978-3-319-50030-0 1

[31] Liu, M., Navarrete, C. C., \& Wivagg, J. (2014). Potentials of mobile technology for K-12 education: An investigation of iPod touch use for English language learners in the United States. Journal of Educational Technology \& Society, 17(2).

[32] McLaughlin, B., \& Harrington, M. (1989). Second-language acquisition. Annual Review of Applied Linguistics, 10, 122-134. https://doi.org/10.1017/s0267190500001240

[33] Miyazoe, T. y Anderson, T. (2010). Learning outcomes and students' perceptions of online writing: Simultaneous implementation of a forum, blog, and wiki in an EFL blended learning setting. System: An International Journal of Educational Technology and Applied Linguistics, 38(2), 185-199. https://doi.org/10.1016/j.system.2010.03.006

[34] Nomass, B. B. (2013). The impact of using technology in teaching English as a second language. English Language and Literature Studies, 3(1), 111. https://doi.org/10.5539/ells. v3n1p111

[35] O'malley, J. M., \& Chamot, A. U. (1990). Learning strategies in second language acquisition. Cambridge university press.

[36] Ohkuma, K., Osogami, M., Shiori, N., \& Sugihara, K. (2017). Motivation Effects of Using Actual Robots Controlled by the Scratch Programming Language in Introductory Programming Courses. International Journal of Engineering Education, 33(2), 575-587.

[37] Ortiz-Colon, A. M., \& Romo, J. L. M. (2016). Teaching with Scratch in compulsory secondary education. International Journal of Emerging Technologies in Learning (iJET), 11(02), 67-70. https://doi.org/10.3991/ijet.v11i02.5094

[38] Palma, C. M. (2016). Teaching Spanish as a foreign language: tools and resources for the modern ELE teacher. International Journal of Research and Education, 1(1), 7.

[39] Persson, V., \& Nouri, J. (2018). A systematic review of second language learning with mobile technologies. International Journal of Emerging Technologies in Learning (iJET), 13(2). https://doi.org/10.3991/ijet.v13i02.8094 
[40] Richards, J. C. (2015). Error analysis: Perspectives on second language acquisition. Routledge.

[41] Salaberry, M. R. (2001). The use of technology for second language learning and teaching: A retrospective. The Modern Language Journal, 85(1), 39-56. https://doi.org/10.1111/0026 $-7902.00096$

[42] Solihati, N., \& Mulyono, H. (2017). A Hybrid Classroom Instruction in Second Language Teacher Education (SLTE): A Critical Reflection of Teacher Educators. International Journal of Emerging Technologies in Learning, 12(5). https://doi.org/10.3991/ijet.v12i05. $\underline{6989}$

[43] Suk, N. (2017). The Effects of Extensive Reading on Reading Comprehension, Reading Rate, and Vocabulary Acquisition. Reading Research Quarterly, 52(1), 73-89. https://doi. org/10.1002/rrq. 152

[44] Van Essen, A., Jager, S., \& Nerbonne, J. (Eds.). (2014). Language teaching and language technology. Routledge.

[45] Von Ahn, L. (2013). Duolingo: learn a language for free while helping to translate the web. In Proceedings of the 2013 international conference on Intelligent user interfaces (pp. 1-2). ACM. https://doi.org/10.1145/2449396.2449398

[46] Walker, L. (2016). The impact of using Memrise on student perceptions of learning Latin vocabulary and on long-term memory of words. Journal of Classics Teaching, 16(32), 1420. https://doi.org/10.1017/s2058631015000148

[47] Wang, Y. (2004). Supporting synchronous distance language learning with desktop videoconferencing. Language Learning \& Technology, 8(3), 90-121.

[48] Wang, S., \& Smith, S. (2013). Reading and grammar learning through mobile phones. Language Learning \& Technology, 17(3), 117-134.

[49] West, J. A., \& West, M. L. (2009). Using wikis for online collaboration: The power of the read-write web. John Wiley \& Sons

\section{Authors}

Antonio Sarasa Cabezuelo, has a MS. degree on Mathematics of Computer Sciences from the Complutense Universtiy of Madrid, BS. degree on Computer Sciences from the National University of Distance Education, MS. degree on Computer Sciences from the Open University of Catalonia and CS PhD from the Complutense University of Madrid. Currently, he is an associate professor in the Computer Science School at Complutense University of Madrid, and a member of the research group ILSA (Implementation of Language-Driven Software and Applications, , http://ilsa.fdi.ucm.es). His research is focused on e-Learning, markup languages and Domain-specific languages. He was one of the developers of the Agrega project on digital repositories. He has published over 50 research papers in national and international conferences. Likewise, he is a member of the 36 Subcommittee of AENOR.

Article submitted 2019-07-07. Resubmitted 2019-08-12. Final acceptance 2019-08-13. Final version published as submitted by the authors. 